\title{
AVALIAÇÃO DA TOXIDADE DA ÁGUA E SEDIMENTO DO AÇUDE JABURU (CEARÁ-BR) NA REGIÃO DO SEMI- ÁRIDO
}

\author{
WATER AND SEDIMENT TOXICITY ASSESSMENT OF \\ THE JABURU RESERVOIR (CEARÁ-BR) IN THE SEMI- \\ ARID REGION
}

\section{Priscila Maria Dellamatrice ${ }^{1}$, Lilian da Silva $\operatorname{Costa}^{1}$, Milena Viana de Sousa ${ }^{1}$, Rinaldo dos Santos Araújo ${ }^{1}$}

${ }^{1}$ Laboratório de Tecnologia Ambiental, IFCE, Av. Treze de Maio, 3081, 60040-531, Fortaleza, CE, Fone: (85)3401-2300. E-mail: rinaldo@ifce.edu.br

\begin{abstract}
RESUMO
Os açudes são o único recurso disponível para abastecimento de água da população na região semiárida durante a estação seca. Esse recurso, porém, também é utilizado na agricultura desenvolvida no entorno do açude, para irrigação. Devido ao uso contínuo de fertilizantes e pesticidas, esses produtos podem ser carreados para as águas, poluindo-as. O Açude Jaburu, localizado na região noroeste do Estado do Ceará, é responsável pelo abastecimento de oito cidades e oito vilas e distritos. Nele, foram realizados testes de toxicidade aguda na água e sedimento, utilizando os organismos Daphnia magna, a alga Pseudokirchneriella subcapitata e sementes de alface (Lactuca sativa). Foi também realizado o teste crônico na água com Daphnia magna. Foram analisados três pontos em três diferentes profundidades para verificar efeito da estratificação, nos períodos de seca e cheia. Toxicidade aguda da água não foi detectada em nenhum dos pontos amostrados. No teste de toxicidade crônica, foi detectada toxicidade nos dois períodos, seca e cheia, sendo mais pronunciado no primeiro. No sedimento, houve toxicidade aguda somente no período de seca para $D$. magna, enquanto para os outros organismos não houve toxicidade. Os resultados demonstraram que o Açude Jaburu ainda não se encontra severamente impactado, porém os testes de toxicidade crônica mostram que pode estar sofrendo poluição por compostos químicos em baixas concentrações e poderá causar dano em longo prazo. Propõe-se um melhor gerenciamento ambiental desse recurso, visando mitigar os impactos ambientais negativos nesse ecossistema.
\end{abstract}

Palavras-chave: Açude. Água. Sedimento. Toxicidade. Pesticidas

\begin{abstract}
The reservoirs are the only resource available to people supply in semi-arid region during the dry season. However, these reservoirs are also used for crop irrigation, which is done on the vicinity of the reservoir. Due to the continuous use of fertilizers and pesticides, these products are carried to the water polluting them. The Jaburu reservoir, located in northwestern of Ceará' State, is used for supplying eight cities and eight villages and districts. Acute toxicity tests were done in this reservoir on water and sediment, using the organisms Daphnia magna, algae Pseudokirchneriella subcapitata and lettuce seeds, and also chronic toxicity test in the water with Daphnia magna. It was assessed
\end{abstract}


three points in three different depths to determine the stratification effect, during the dry and rainy seasons. Acute toxicity was not detected in the water in the all sampled points. In the chronic test, toxicity was detected in both periods, dry and rainy, and it was more severe during the dry season. In the sediment, there was acute toxicity in water during the dry season for only D. magna, while for the other organisms no toxicity was detected. Results showed that the Jaburu reservoir was not severely impacted yet, but the chronic tests showed contamination of water by pollutants in low concentrations, causing long-term effect. Appropriate regulatory management should be done to prevent future impact on this ecosystem.

Keywords: Dam. Water. Sediment. Toxicity. Pesticide.

\section{INTRODUÇÃO}

Crescente atividade agrícola com uso intensivo de agroquímicos nas vizinhanças de corpos de água tem causado poluição destes ecossistemas aquáticos. A agricultura polui a água com fertilizantes, inseticidas, fungicidas, herbicidas e nitrato, que são carregados pela chuva ou infiltrados no solo contaminando os mananciais subterrâneos e os lençóis freáticos (FERREIRA, 2005). O ambiente aquático não é um compartimento de diluição infinita da poluição gerada e a superfície da terra e seus ambientes nada mais são do que compartimentos frágeis de matéria viva dos quais depende a existência humana. A quantidade e diversidade de produtos químicos aumentam a probabilidade dos riscos nestes ambientes (ZAGATTO, 2006).

Quantificar estes produtos e determinar seus reais efeitos sobre os organismos só é possível com a combinação de métodos químicos e ecotoxicológicos, onde apenas determinações químicas predizem a quantidade de químicos presentes, mas não se estes são os verdadeiros causadores do efeito, o qual só pode ser determinado aliado aos testes ecotoxicológicos (CAMPAGNA et al., 2008). O ideal é demonstrar a presença de efeitos adversos mediante os bioensaios, que são capazes de integrar em suas respostas efeitos interativos de fatores físico-químicos e biológicos, e a partir daí proceder com análises químicas para estabelecer relações mais diretas entre os efeitos detectados e contaminantes específicos (BLAISE e FÉRARD, 2005).

Além dos efeitos letais, avaliados em testes agudos, igualmente importantes são os subletais, refletindo sobre reprodução e comportamento, os quais podem repercutir sobre a sobrevivência de populações e comunidades (LENIHAM et al., 1995). Efeitos crônicos são importantes para avaliar a comunidade em longo prazo (CAMPAGNA et al., 2008). Modificações da estrutura são mais comuns que a letalidade em ambientes impactados com baixas doses, porém constantes.

Os períodos de chuva são sempre acompanhados de aumentos bruscos de nutrientes e matéria orgânica dentro dos reservatórios (RODGHER et al., 2005). A presença de pesticidas na água pode obedecer a um modelo sazonal que depende do tempo de aplicação e mecanismo de transporte. Frequentemente, os pesticidas são aplicados em uma estação e transportados para as águas superficiais no mesmo período, apenas dias ou semanas após. Típico modelo sazonal inclui aumento da concentração nas primeiras chuvas e final da estação, com acúmulo dos pesticidas transportados durante toda a estação (KUIVILA e HLADIK, 2008).

Além dos efeitos deletérios que ocorrem nesses períodos, poluentes podem se acumular nos sedimentos, causando efeito por longos períodos. Estes podem ser mobilizados novamente e retornar a coluna de água onde os organismos ficaram novamente expostos a eles. Sedimentos são complexas misturas de numerosos potenciais tóxicos, todos causadores de efeito e um único causador de toxicidade é muito difícil de determinar, sendo considerado o efeito global de todos os poluentes presentes. Vários poluentes estão presentes em baixas concentrações e juntos causam 
toxicidade. Mesmo componentes naturais do sedimento como amônia e sulfetos podem causar toxicidade (THOMPSON et al., 1999).

Os reservatórios são sistemas complexos entre os rios e lagos e são partes integrantes de uma bacia hidrográfica. Assim, eles sofrem todos os impactos das atividades antropogênicas ao longo da bacia (TUNDISI e STRASKRABA, 1999). Os fatores como $\mathrm{pH}$, condutividade, dureza, oxigênio dissolvido e temperatura, são utilizados para monitoramento da qualidade das águas, e avaliam momentaneamente também o ecossistema aquático (ALVES et al., 2006).

Processos limnológicos de circulação, estratificação e mistura desempenham importante papel na distribuição das substâncias dentro do lago. O volume da água dentro do sistema também afeta a distribuição, pois quanto maior o volume de água, maior o tempo de homogeneização no meio e menor a concentração final pelo efeito de diluição. Características da bacia tais como extensão das margens e seu desenvolvimento, profundidade, área da bacia e configuração podem dar origem a condições localizadas capazes de afetar a concentração das substâncias tóxicas no meio (MATSUI et al., 2002).

Neste trabalho estudou-se o Açude Jaburu, o qual serve de fonte de água para abastecimento da população, e é também utilizado como recurso para desenvolvimento agrícola na região, mediante a utilização das suas águas para irrigação. O objetivo deste trabalho foi avaliar o impacto de atividades agrícolas, principalmente pesticidas, sobre as águas do Açude Jaburu aplicando-se bioensaios de toxicidade aguda e crônica na água e sedimento.

\section{MATERIAL E MÉTODOS}

\subsection{Local}

O Açude Jaburu está localizado no Município de Tianguá, Estado do Ceará, e possui volume máximo de 210 milhões de metros cúbicos, pertencendo à bacia hidrográfica do Parnaíba (Figura 1). É responsável pelo abastecimento de oito cidades, beneficiando ainda 8 vilas e distritos e uma cidade pertencente ao estado do Piauí, sendo o ponto de coleta da água localizado no Município de Tianguá.

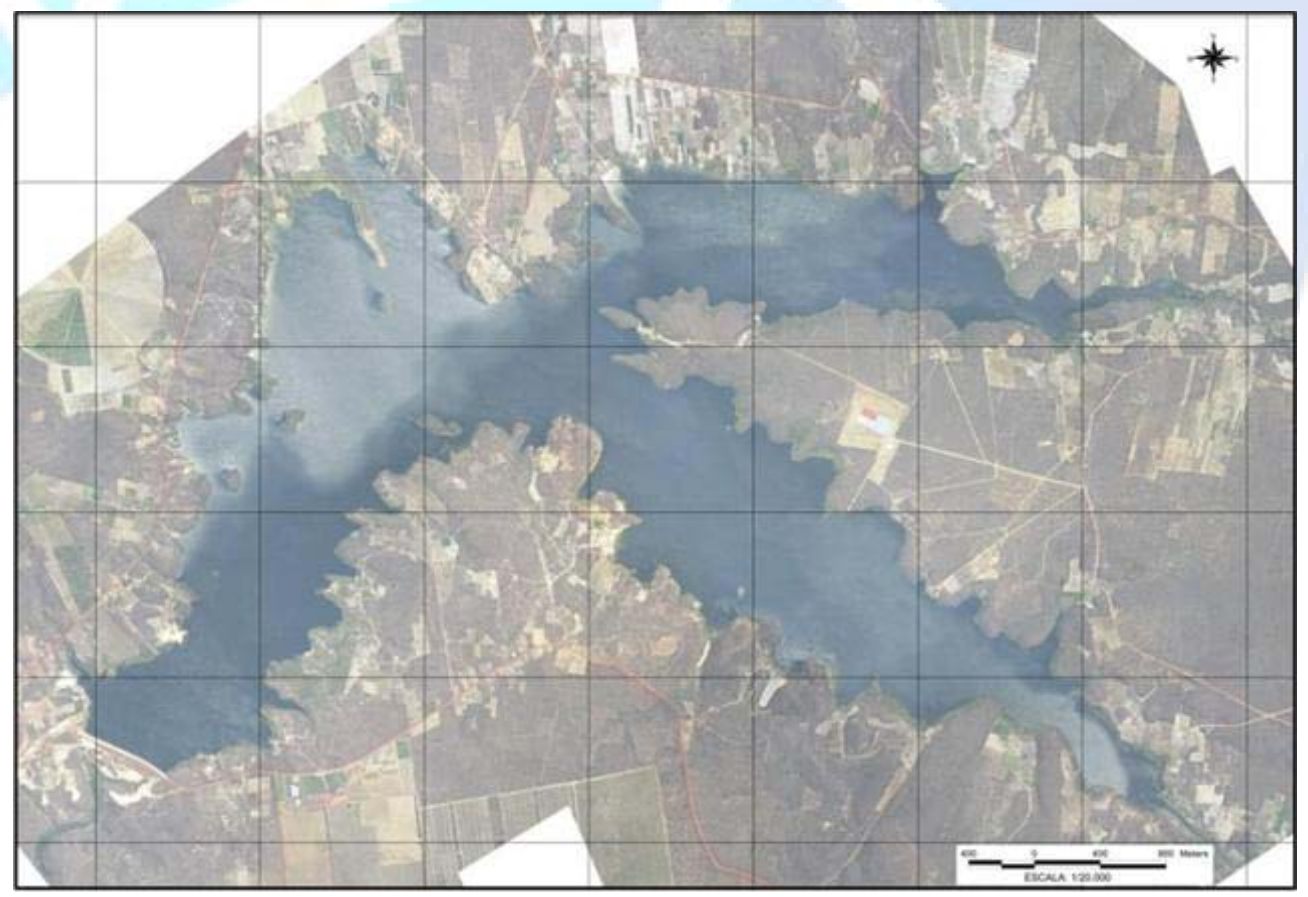

Figura 1. Visão aérea do Açude Jaburu localizado no município de Tianguá-CE (coordenadas 265.233E e 9.572.510N). Fonte: Sousa e Malveira (2011). 
Análises toxicológicas da água foram realizadas em três pontos localizados na entrada, meio e saída do açude. Em cada ponto, foram amostradas três profundidades, superfície, meio e fundo (Tabela 1), durante os períodos de seca e de cheia. As coletas foram feitas em garrafa de van Dorn e as amostras de água e de sedimento foram conservadas em gelo até o laboratório. O sedimento foi coletado com draga Eickmann-Birge, colocado em sacos plásticos e mantido em gelo até o laboratório, onde permaneceu refrigerado até a realização das análises.

Tabela 1 - Pontos de amostragem (entrada, centro e saída) e profundidades (superfície, meio e fundo).

\section{Profundidade por ponto amostrado}

\begin{tabular}{lccc} 
Profundidade & $\begin{array}{c}\text { Entrada } \\
\text { (Ponto 1) }\end{array}$ & $\begin{array}{c}\text { Centro } \\
\text { (Ponto 2) }\end{array}$ & $\begin{array}{c}\text { Saída } \\
\text { (Ponto 3) }\end{array}$ \\
\hline A (superfície) & 0,3 & 0,3 & 0,3 \\
B (meio) & 6,5 & 7,5 & 3,5 \\
C (fundo) & 12,9 & 14,8 & 6,8
\end{tabular}

\subsection{Tratamento das amostras de sedimentos para os bioensaios}

As amostras de sedimento provenientes dos pontos de coleta foram pesadas e distribuídas em recipientes mantendo-se a proporção de 4:1 (peso) de água mineral e sedimentos, respectivamente. Após sedimentar por 24 horas, foi retirado o líquido sobrenadante. A partir desta solução (100\%) foram feitas diluições para 75; 50 e 25\% para exposição dos organismos testes. Foram feitos testes de toxicidade aguda com Daphnia magna, Selenastrum capricornutum e sementes de Lactuca sativa (alface).

\subsection{Teste de toxicidade aguda para água e sedimento}

\subsubsection{Teste de toxicidade aguda com Pseudokirchneriella subcapitata (BLAISE et al., 2000)}

A alga Pseudokirchneriella subcapitata obtida na Coleção de Cultura Americana (USA ATCC n. ${ }^{\circ}$ 22662) é cultivada em cultura continua no laboratório. Esta foi incubada sob iluminação contínua com lâmpada fria fluorescente $(4000 \pm 10 \%$ lux $)$ a $25 \pm 2^{\circ} \mathrm{C}$ e agitada manualmente por poucos segundos, três vezes ao dia. O inóculo foi obtido no quinto dia de repicagem, onde a partir da contagem das algas, com auxílio de um hematocitômetro e microscópio óptico, foram obtidas soluções com densidade de $2,6 \times 10^{5}$ cel. $\mathrm{mL}^{-1}$.

O volume de $100 \mu \mathrm{L}$ desta solução foi transferido para frascos contendo $2,5 \mathrm{~mL}$ de amostra, as quais foram filtradas em membrana (Millipore- $0.22 \mu \mathrm{m}$ ), nas diluições de 100, 75, 50 e 25\%. Estes frascos foram vedados com filme plástico transparente e incubados em luminosidade contínua $(4000 \pm 10 \% \operatorname{lux})$, a $25^{\circ} \mathrm{C}$ e por 72 horas, sendo agitados manualmente três vezes ao dia. No final, a partir da contagem do número de algas, foi determinado a $\mathrm{CI}_{50}$, que é a concentração que apresenta efeito sobre $50 \%$ dos indivíduos analisados.

\subsubsection{Teste de toxicidade aguda com sementes de Lactuca sativa (alface) (DUTKA, 1989)}

As amostras filtradas através de membrana (Millipore-0.22 $\mu \mathrm{m}$ ) foram diluídas nas concentrações de $100,75,50$ e $25 \%$ em água mineral e $2 \mathrm{~mL}$ de cada solução foram utilizados para embeber discos de papel de filtro colocados no interior de placas de poliestireno $(9 \mathrm{~cm} \varnothing)$. Foram colocadas 20 sementes de alface em cada placa. As placas foram envoltas em folha alumínio e após 
$48 \mathrm{~h}$ foi realizada a avaliação do tamanho das raízes germinadas, com auxílio de papel milimetrado. A partir destes valores foi calculada a CI50.

\subsubsection{Teste de toxicidade aguda com Daphnia magna (DUTKA, 1989)}

A partir da amostra foram preparadas diluições (100; 75; 50 e 25\%) e um controle negativo. Em cada recipiente, em três réplicas, foram colocados $30 \mathrm{~mL}$ da diluição onde foram colocados 5 neonatos de $24 \mathrm{~h}$ de idade, evitando-se transferir excesso de líquido. Os recipientes foram recobertos com Vinipel transparente, mantidos a $21 \pm 2^{\circ} \mathrm{C}$ sob intensidade luminosa de 800 lux e fotoperíodo de $16 \mathrm{~h}$ luz por $8 \mathrm{~h}$ escuro. Após $48 \mathrm{~h}$, foi feita a contagem dos organismos mortos por concentração para determinação da concentração que produz $50 \%$ de mortalidade $\left(\mathrm{CL}_{50}\right)$.

\subsection{Teste de toxicidade crônica da água - Daphnia magna}

Os neonatos foram colocados em copos de $50 \mathrm{~mL}$ de capacidade, sendo introduzido um organismo por recipiente, em 10 repetições. Em cada recipiente foram colocados $20 \mathrm{~mL}$ da amostra não diluída. Os copinhos foram cobertos com filme plástico. A alimentação foi diária, tendo sido mantida a mesma proporção do cultivo. A água foi trocada a cada dois dias, inclusive o controle. Foi feita contagem dos neonatos produzidos durante o teste e avaliada a mortalidade das mães no período.

\subsection{Análises físicas e químicas da água}

Foram monitoradas algumas variáveis físicas e químicas, como o $\mathrm{pH}$, oxigênio dissolvido, condutividade elétrica e temperatura da água, utilizando sonda YSI $6600 \mathrm{~V} 2$, para verificar as condições da água no momento da coleta (APHA, 2005).

\section{RESULTADOS E DISCUSSÃO}

\subsection{Teste de toxicidade aguda da água}

Nos testes de toxicidade aguda realizados com os três organismos estudados (Daphnia magna, a alga Pseudokirchneriella subcapitatae sementes de alface) não houve alteração sobre os organismos para nenhuma das amostras coletadas nos três pontos do açude, nas três profundidades e nos diferentes períodos ao longo de um ano, sobre os organismos testados. Não foi detectada a presença de substâncias tóxicas aos organismos testados na água. Isto indica que as águas do Açude Jaburu não apresentam contaminação severa por poluentes capazes de comprometera viabilidade dos organismos.

\subsection{Teste de toxicidade aguda do sedimento}

Foi detectada toxicidade aguda no sedimento apenas no período de seca somente para $D$. magna, a qual foi detectada nos pontos 2 e 3, correspondendo ao centro e saída do Açude. Foi determinada a $\mathrm{CL}_{50}$ para os dois pontos: no ponto 2 a $\mathrm{CL}_{50}$ foi de $56,98 \%$ e para o ponto 3 foi de $84,79 \%$. O ponto 1 (JB-02), que corresponde a entrada, e o ponto 2 (JB-07) que corresponde ao centro estão localizados próximo a margem esquerda, onde ocorre maior número de áreas com diversidade agrícola, podendo estar sofrendo poluição por carreamento dos pesticidas utilizados. No ponto 1 (entrada), o fluxo das águas ocorre em direção aos pontos 2 e 3 (centro e saída), sendo que o maior acúmulo de material ocorre no ponto 3 (barragem do açude), no qual também foi detectada toxicidade. O centro do açude concentrou a maior parte dos poluentes, refletido no maior efeito tóxico para D.magna. No período de cheia não foi detectada toxicidade no sedimento, mostrando que esta não é permanente, sendo eliminada com a renovação das águas. 
Estes resultados estão em acordo com os encontrados por COELHO \& ROCHA (2008), que também detectaram toxicidade nos sedimentos do reservatório do Lobo e lagoa Dourada próximo a barragem, na saída do reservatório.

\subsection{Teste de toxicidade crônica da água - Daphnia magna}

Nos testes de toxicidade crônica da água, esta foi detectada nos períodos, seca e cheia, sendo mais pronunciada no primeiro. Neste último ocorreu maior concentração de poluentes devido ao menor volume de água. A mortalidade dos organismos foi alta no período da seca, sendo que esta foi mais severa nas camadas mais profundas (Figura 2). Partículas associadas com poluentes que são carreadas das margens para dentro do açude tendem a ser acumuladas no fundo da lagoa, causando maior toxicidade nas camadas mais profundas do açude. Os pontos 2 e 3 foram novamente os que apresentaram maior toxicidade, sendo que o efeito tóxico pode estar sendo causado pelo fluxo das águas da entrada em direção à saída. No período de cheia, a mortalidade foi significativamente menor, mostrando que a renovação das águas diminuiu a toxicidade.

No estudo realizado por Gobbato et al. (2008) houve mortalidade elevada do organismo teste $D$. similis usando a água do rio Camburi (São Sebastião, SP), a qual ocorreu principalmente no período seco, enquanto nenhum efeito tóxico foi detectado no período chuvoso. Também Costa e Espíndola (2000) encontraram maior toxicidade no período de seca para Ceriodaphnia dúbia e Ceriodaphnia silvestrii em estudos realizados no rio Tietê até a barragem de Barra Bonita.

\section{organismos vivos}

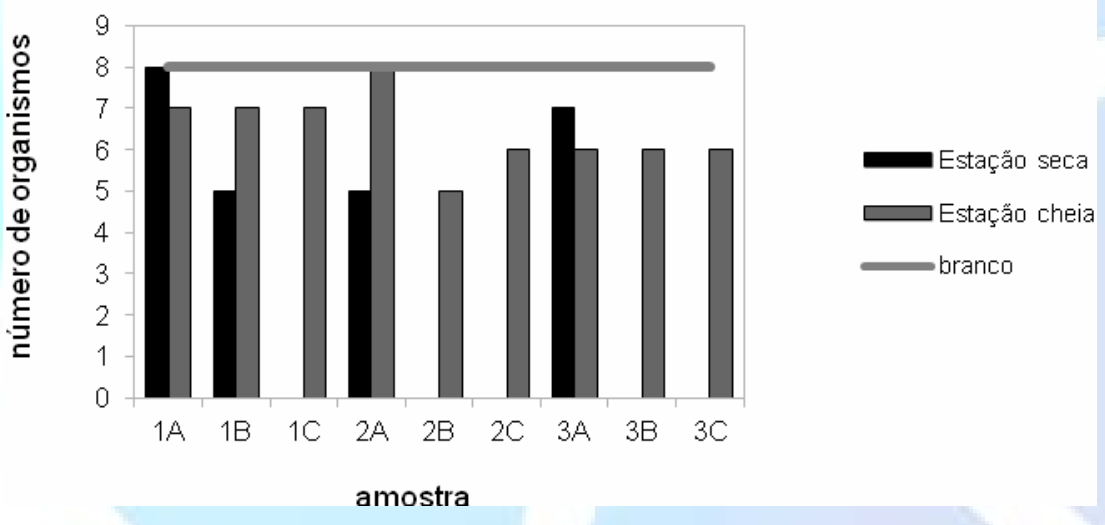

Figura 2. Número de organismos vivos (D. magna) para a época cheia e seca detectadas nas amostras de superfície (A), centro (B) e fundo (C), nos pontos 1 (entrada), 2 (centro) e 3 (saída) da água do Açude Jaburu-CE

No trabalho de Soares e Porto (2007), a ocorrência de pesticidas na água causada por escoamento superficial dependeu principalmente da proximidade com as áreas de cultivo. Neste estudo, maior toxicidade foi encontrada no ponto 1 , onde há maior ocorrência de áreas agrícolas na proximidade.

O efeito sobre o número de neonatos produzidos também foi maior no período de seca, onde não houve nascimento de destes em nenhuma das amostras, somente no controle (21 organismos). No período de cheia, o efeito tóxico foi menor, sendo mais pronunciado no ponto 2 , centro do açude, nas três profundidades. Nos pontos 1 e 3 o número de neonatos foi menor do que no controle (30 organismos), mas a toxicidade foi significativamente menor (Figura 3). O maior acúmulo de poluentes no centro do Açude, provavelmente é induzido pelo fluxo de água da entrada para a saída do Açude. 
No período de cheia, o maior volume de água dentro do açude contribui para a diluição das águas e diminuição da toxicidade. No período de seca, há maior concentração dos poluentes e estes podem induzir a toxicidade.

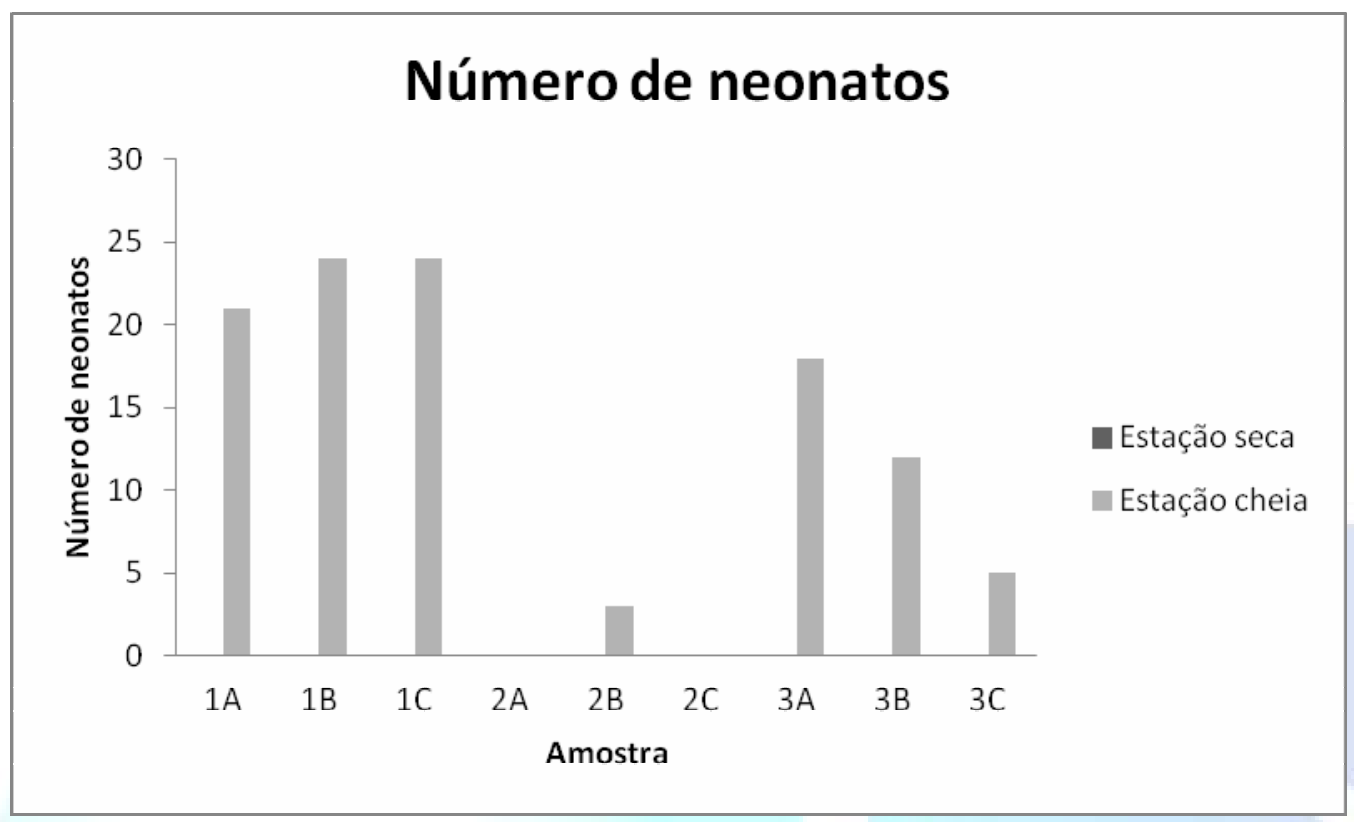

Figura 3. Número de neonatos produzidos na época de seca e cheia detectadas nas amostras de superfície (A), centro (B) e fundo (C), nos pontos 1 (entrada), 2 (centro) e 3 (saída) da água do Açude Jaburu - CE

\subsection{Análises físicas e químicas da água}

\subsubsection{Temperatura}

A temperatura teve pequena variação tanto no período de cheia e como na de seca. A temperatura no período de cheia e seca apresentou ligeiro declínio no ponto $\mathrm{C}$, resultado da estratificação entre camadas. No período de cheia a variação foi maior do que na época na seca (Figura 4).

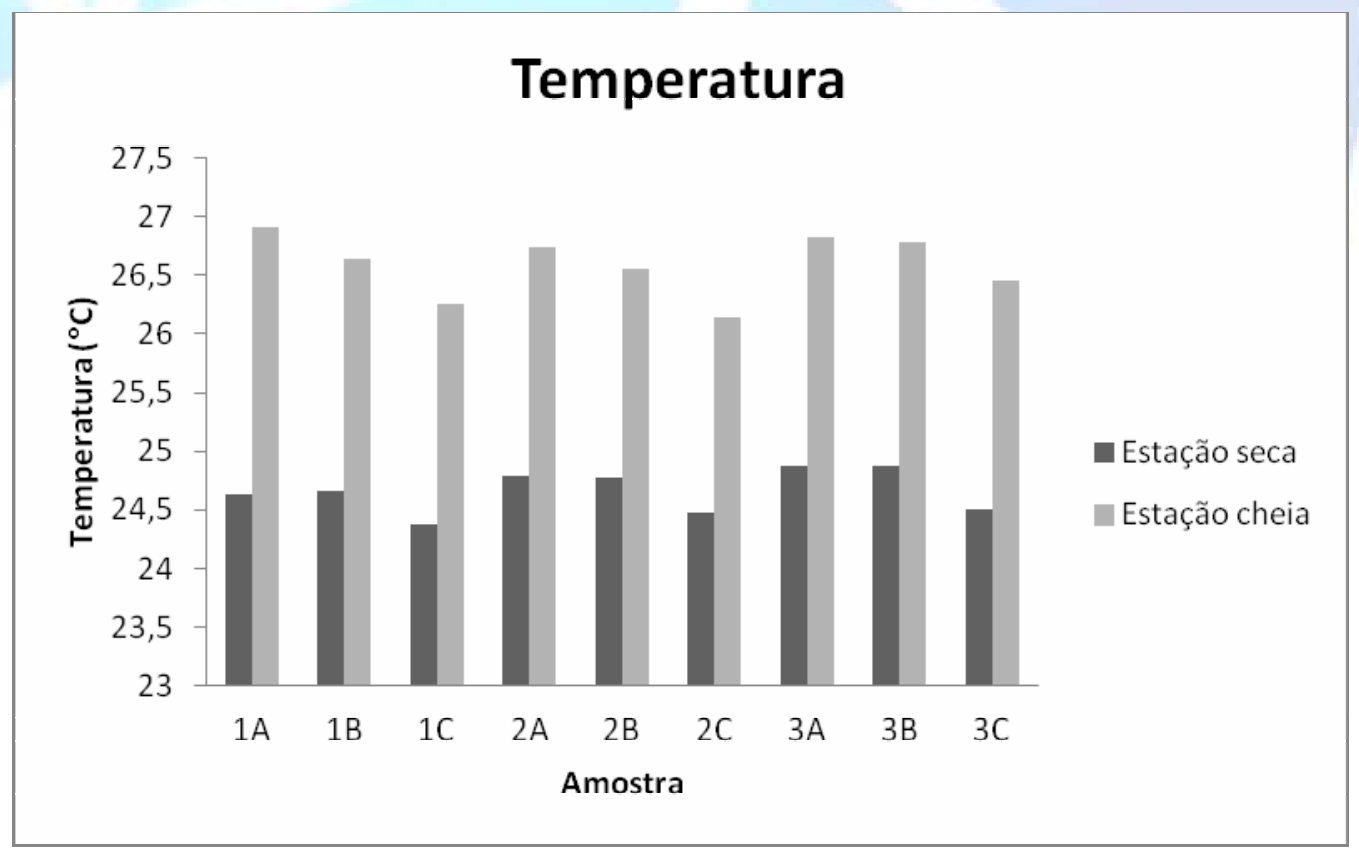

Figura 4. Valores da temperatura da água do Açude Jaburu - CE na estação seca e cheia nas amostras de superfície (A), centro (B) e fundo (C), nos pontos 1 (entrada), 2 (centro) e 3 (saída) 


\subsection{2. $\mathrm{pH}$}

Os valores de $\mathrm{pH}$ encontrados nas amostras de superfície (A), centro (B) e fundo (C) não diferiram mantendo-se em pequena variação em cada amostra (Figura 5). As camadas mais profundas apresentaram $\mathrm{pH}$ ligeiramente menor, causado provavelmente pela degradação da matéria orgânica no fundo, acarretando formação de ácidos. Os valores de $\mathrm{pH}$ caracterizam a água do açude como de $\mathrm{pH}$ neutro. Este fator na estação úmida foi sempre menor, o que segundo Rodgher et al. (2005), ocorre devido a maior incidência de chuvas ácidas.

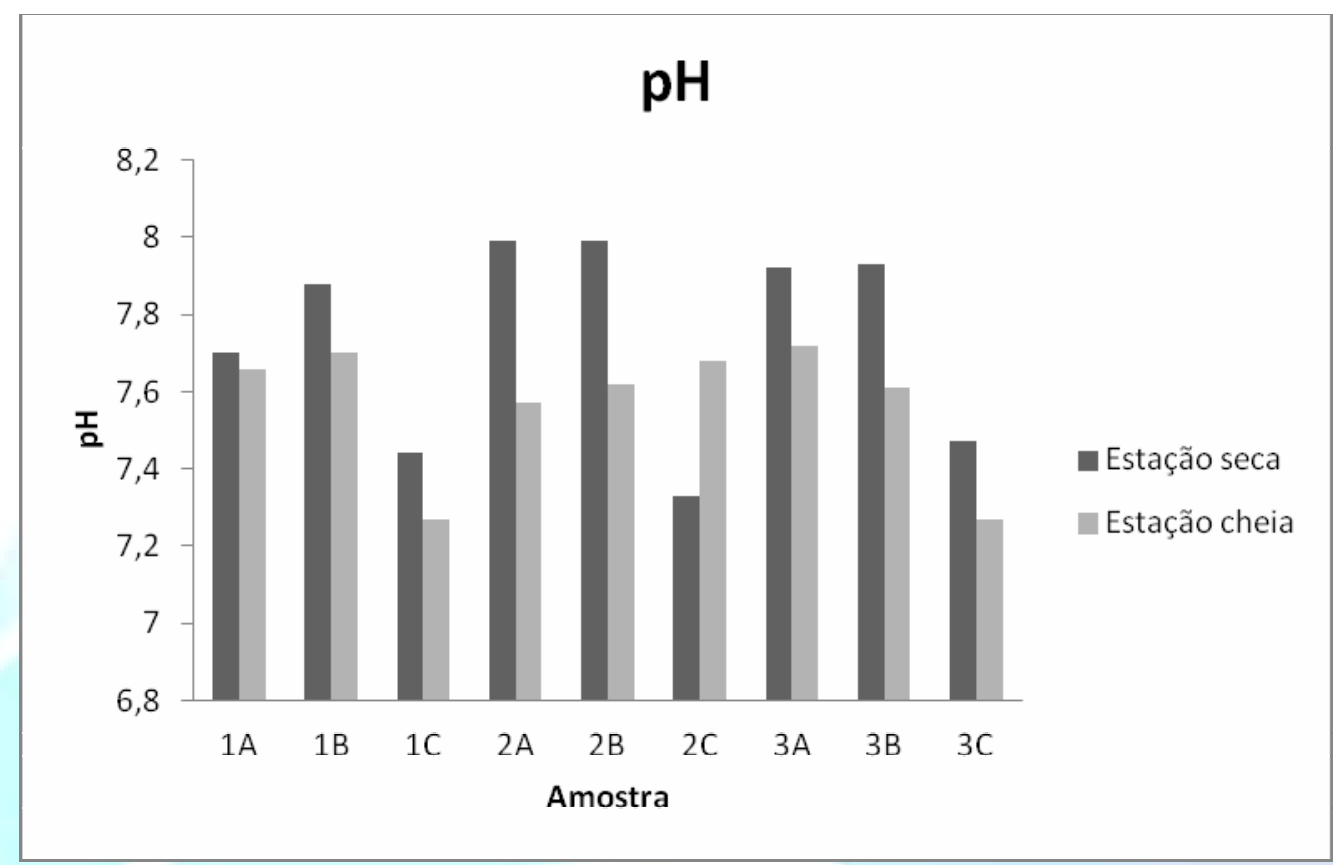

Figura 5. Valores do $\mathrm{pH}$ das águas coletadas do Açude Jaburu - CE na estação seca e cheia nas amostras de superfície (A), centro (B) e fundo (C), nos pontos 1 (entrada), 2 (centro) e 3 (saída)

\subsubsection{Condutividade Elétrica}

A condutividade elétrica indica a quantidade de sais existentes na coluna de água, representando assim uma medida indireta da concentração de poluentes. Em geral, níveis superiores a $100 \mu \mathrm{S} / \mathrm{cm}$ indicam ambientes impactados. Neste caso as águas do açude contém grande quantidade de sais, principalmente na estação cheia, resultado do carreamento de materiais das margens pela água da chuva nesta época. Nos dois casos a condutividade se mantém pouco variável entre camadas dentro do açude (Figura 6). 


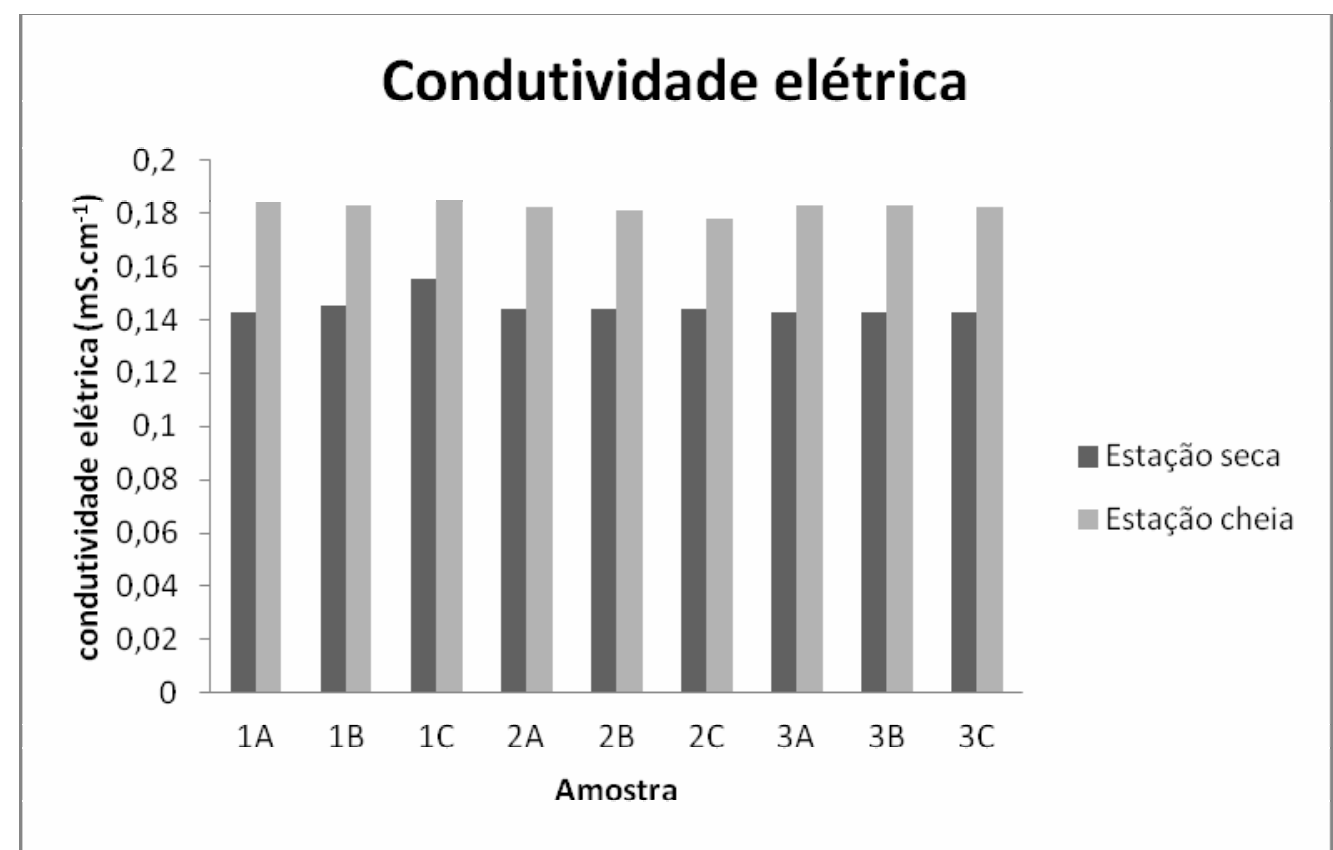

Figura 6. Valores da condutividade elétrica da água do Açude Jaburu - CE na estação seca e cheia nas amostras de superfície (A), centro (B) e fundo (C), nos pontos 1 (entrada), 2 (centro) e 3 (saída)

\subsubsection{Oxigênio Dissolvido (OD)}

Em ambas as coletas dos períodos de seca e cheia os valores para OD sofreram significativa diminuição nas camadas mais profundas, devido a degradação aeróbia da matéria orgânica no sedimento de fundo (Figura 7). Na época de cheia, a diminuição foi menor, o que está de acordo com Rodgher et al. (2005) que relataram maior degradação de matéria orgânica e consumo de $\mathrm{O}_{2}$ na estação seca. Nas camadas superiores os valores foram sempre maiores, indicando que há estratificação neste açude e as águas não são misturadas entre as camadas. No verão, as altas temperaturas tendem a aumentar o consumo de oxigênio. De acordo com a Resolução Conama 357/2005 (BRASIL, 2005), regulamentada pela Portaria MS 2914/2011, o limite mínimo para oxigênio dissolvido é $4 \mathrm{mg} / \mathrm{L}$, estando os valores encontrados dentro do recomendado.

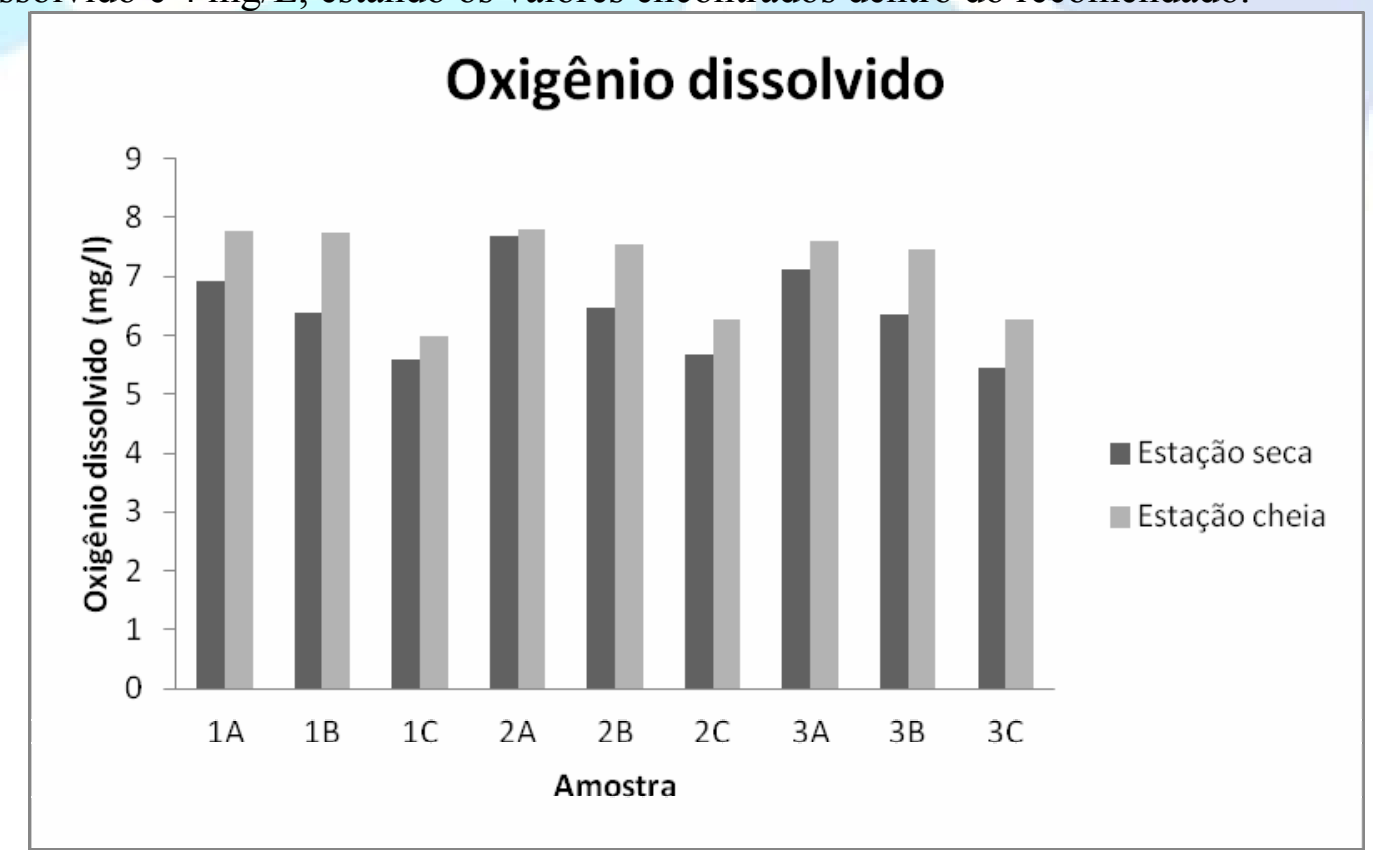

Figura 7. Valores de oxigênio dissolvido da água do Açude Jaburu - CE na estação seca e cheia nas amostras de superfície (A), centro (B) e fundo (C), nos pontos 1 (entrada), 2 (centro) e 3 (saída) 


\section{CONCLUSÕES}

Os resultados demonstraram que o Açude Jaburu - CE ainda não está severamente impactado, porém os testes de toxicidade crônica mostram que este ecossistema pode estar sofrendo contaminação por poluentes em baixas concentrações, causando efeito em longo prazo. $\mathrm{O}$ sedimento apresentou toxicidade, mas esta não foi permanente. $\mathrm{O}$ período de seca apresentou maior efeito, causado principalmente pela concentração de poluentes nas águas. Gerenciamento adequado destes recursos deve ser feito visando conter os impactos sobre as águas.

\section{REFERÊNCIAS}

\section{ALVES, C.L.; FAGUNDES, A.S.M.; SANTOS, A.P.M.; MAKINO, D.L.; OLIVEIRA NETO,} A.L.. Avaliação Ecotoxicológica de Pesqueiros Localizados no Município de Serra Negra SP. In: $3^{\circ}$ Seminário Internacional de Ciência e Tecnologia na América Latina - A Universidade como Promotora do Desenvolvimento Sustentável, 2006, Campinas. Caderno de Resumos do $3^{\circ}$ Seminário Internacional de Ciência e Tecnologia na América Latina. Campinas: EditoraUnicamp, 2006. v. 1. p. 28-25.

ALVES M.I.R; ANTONIONI FILHO N.R; OLIVEIRA L.B; FURTADO S.T.F. Avaliação da contaminação por pesticidas organoclorados em recursos hídricos do Estado de Goiás. Revista Brasileira de Recursos Hídricos, v. 15, n. 1, p. 67-74, 2010.

APHA. American Public Health Association. Standard methods for the examination of water and wastewater., $20^{\circ}$ Edition. APHA, 2005. 1336 p.

BLAISE, C.; FERARD, J.F. Small-scale freshwater toxicity investigations, v. 1.Toxicity test methods. Dordrecht: Springer Science, 2005, 551 p.

BLAISE, C., FORGET, G.; TROTTIER, S. Toxicity screening of aqueous samples using a costeffective $72 \mathrm{~h}$ exposure Selenastrum capricornutum assay. Technical Methods, v.15, n.4, p.352$359,2000$.

BRASIL. Ministério do Meio Ambiente, Conselho Nacional do Meio Ambiente - CONAMA (2005), Resolução n. 357, de 17 de março de 2005. Dispõe sobre a classificação dos corpos de água e diretrizes ambientais para o seu enquadramento, bem como estabelece as condições e padrões de lançamento de efluentes, e dá outras providências. Diário Oficial da República Federativa do Brasil, Poder Executivo, Brasília, DF, 18 mar. 2005. Seção 1, p.58-63.

CAMPAGNA, A.F.; FRÁCÁCIO, R.; RODRIGUES, B.K.; ELER, M.N.; VERANI, N.F.; ESPÍNDOLA, E.L. Analyses of the sediment toxicity on Monjolinho river, São Carlos, São Paulo State, Brazil, using survey, growth and gill morphology of two fish species (Daniorerioand Poeciliareticulata). Brazilian Archives Of Biologyand Technology, v. 51, p. 193-201, 2008.

COELHO, K.S.; ROCHA, O. Avaliação ecotoxicológica da água e sedimento do reservatório do Lobo (Itirapina, SP) e lagoa Dourada (Brotas, SP). III workshop de ecotoxicologia, Holos Environment, Rio Claro, v. 8, n. 2, 2008. Suplemento.

COSTA, J.B.; ESPÍNDOLA, E.L.G. Avaliação ecotoxicológica da água e sedimento em tributários do reservatório de Barra Bonita (Médio Tietê Superior, SP). In: ESPÍNDOLA, E.L.G.; 
PASCHOAL, C.M.R.B.; ROCHA, O; BOHRER, M.B.C.; OLIVEIRA-NETO, A.L. (Editores). Ecotoxicologia - Perspectivas para o Século XXI. Editora Rima, São Carlos, p.75-93, 2000.

DUTKA, B.J. In: Methods for microbiological and toxicological analysis of waters, wastewaters and sediments. National Water ResearchInstitute (NWRI), Environmental Canada, $1989,127 \mathrm{p}$.

FERREIRA, C.M. A importância da água e sua utilização em cenários comerciais. Centro de Pesquisa e Desenvolvimento de Peixes Ornamentais. Panorama da Aquicultura, v. 13, p 15-17, 2005.

GOBBATO, G.M.; CORTEZ, F.S.; SANTOS, A.R.; PEREIRA, C.D.S.; CESAR, A. Avaliação sazonal do toxicidade aguda da água superficial dos rios Camburi e Paraíba, São Sebastião. III workshop de ecotoxicologia, Holos Environment, Rio Claro, v. 8, n. 2, 2008. Suplemento.

KUIVILA, K. M.; HLADIK, M.L. Understanding the occurrence and transport of current-use pesticides in the San Francisco Estuary Watershed. Estuary \& Watershed, v. 6, I 3, article 2, 2008.

LENIHAN, H.S.; KIEST, K.A.; CONLAN, K.E.; SLATTERY, P.N.; KONAR, B.H.; OLIVER, J.S. Patterns of survival and behavior in Antarctic benthic invertebrates exposed to contaminated sediments field and laboratory bioassays. Journal of experimental marine biology and ecology, v.192, p. 233-255, 1995.

MATSUI, S.; BARRETT, B.F.D.; BANERJEE, J. Diretrizes para o gerenciamento de lagos Gerenciamento de substâncias tóxicas em lagos e reservatórios. São Paulo. v. 4. 2002. 216 p.

RODGHER, S.; ESPÍNDOLA, E.L.G.; ROCHA, O.; FRACÁCIO, R.; PEREIRA, R.H.G.; RODRIGUEZ, M.H. Limnological and ecotoxicological studies in the cascade of reservoirs in Tietê river (São Paulo, Brazil). Brazilian Journal of Biology, v.65, p.697-710, 2005.

SOARES,W.L.; PORTO,M.F. Atividade agrícola e externalidade ambiental: uma análise a partir do uso de agrotóxicos no cerrado brasileiro. Revista Ciência e Saúde Coletiva, v. 12, p. 131-143, 2007.

SOUSA, L.N.; MALVEIRA, V.T.C. Monitoramento/Recuperação da fundação da barragem Jaburu I. In: XXVIII Seminário nacional de Grandes Barragens, T103-A10, 2011, Rio de Janeiro. Anais do XXVIII Seminário nacional de Grandes Barragens, Rio de Janeiro: Comitê Brasileiro de Barragens, 2011, p. 1-11.

THOMPSON, B.; ANDERSON, B.; HUNT, J.; TABERSKI, K.; PHILLIPS, B. Relationships between sediment contamination and toxicity in San Francisco Bay. Marine: Environmental Research, v. 48, p. 285-309, 1999.

TUNDISI, J.G.; SHASKRABA, M. Theoretical reservoir ecology and its applications. Brazilian Academy of Sciences International Institut of Ecology and Backhuuis Publishers, 1999, 585 p.

ZAGATTO, P. A. Ecotoxicologia. ZAGATTO, P. A.; BERTOLETTI, E. Ed. Ecotoxicologia Aquática: Princípios e aplicações. Ed. Rima, São Carlos, 2006, 478 p. 